\title{
A POLÍTICA DE REVALIDAÇÃO DE DIPLOMAS ESTRANGEIROS: INTERFACES ENTRE O EXECUTIVO, LEGISLATIVO E JUDICIÁRIO
}

\author{
LA POLÍTICA DE REVALIDACIÓN DE DIPLOMAS EXTRANJEROS: INTERFACES \\ ENTRE EL EJECUTIVO, LEGISLATIVO Y JUDICIAL
}

\author{
THE FOREIGN DIPLOMAS REVALIDATION POLICY: INTERFACES BETWEEN \\ THE EXECUTIVE, LEGISLATIVE AND JUDICIARY
}

\author{
Giselle Cristina Martins REAL ${ }^{1}$ \\ Ana Lucia MARRAN ${ }^{2}$ \\ Kelei $\mathrm{ZENI}^{3}$
}

RESUMO: Objetiva-se aqui delinear o movimento dos Poderes executivo, legislativo e judiciário brasileiro no processo de construção da política de revalidação de diplomas de graduação, que se destaca em contexto globalizado. Partiu-se da análise de documentos produzidos no âmbito desses três Poderes. Observou-se que de 2002 a 2016, há aprovação pelo CNE/MEC de normas disciplinadoras, além da inclusão de exames e da criação da Plataforma Carolina Bori. Em 2011, há a ação do Legislativo federal, que interpõe projeto de lei para fins de revalidação automática. Foram encontrados 3.681 processos nos tribunais de justiça, no entanto, não há manifestação em relação ao mérito da revalidação. O Estado age, vigorosamente, em favor da demanda interna crescente por revalidação e das políticas supranacionais que devem preponderar frente aos aspectos internos das instituições universitárias.

PALAVRAS-CHAVE: Revalidação de diplomas. Política educacional. Educação superior.

RESUMEN: Objectiva aqui delinear el movimiento de los poderes ejecutivo, legislativo y judicial brasileño en el proceso de construcción de la política de revalidación de diplomas de graduación, que se destaca en contexto globalizado. Parte de la analise de documentos produzidos em el âmbito de los três Poderes. De 2002 hasta 2016, hay aprovación per lo $\mathrm{CNE} / \mathrm{MEC}$ de normas disciplinadoras, além de la inclusión de exames y de la criación de la Plataforma Carolina Bori. Em 2011, hay la acción del Lejislativo federal, que interpõe projecto de ley para fins de revalidación automatica. Fueran encontrados 3.681 procesos em los tribunais de justiça, no entanto, não hay manifestación en relacción a lo mérito de la revalidación. Lo Estado actua, vigorosamente, en favor de la demanda interna cresciente por revalidación y de

\footnotetext{
${ }^{1}$ Universidade Federal da Grande Dourados (UFGD), Dourados - MS - Brasil. Docente do Programa de PósGraduação em Educação da UFGD. Doutora em Educação pela USP. ORCID: <http://orcid.org/0000-0002-88554141>. E-mail: gisellereal@ufgd.edu.br

${ }^{2}$ Universidade Estadual de Mato Grosso do Sul (UEMS), Dourados - MS - Brasil. Docente do curso de enfermagem. Doutoranda em Educação na UFGD. Bolsista FUNDECT. ORCID: <http://orcid.org/0000-00017123-9201>. E-mail: anamarran1@ @otmail.com

${ }^{3}$ Centro Universitário da Grande Dourados (UNIGRAN), Dourados - MS - Brasil. Docente do curso de direito. Mestre em Educação pela UFGD. ORCID: <http://orcid.org/0000-0002-4216-3196>. E-mail: keleizeni@yahoo.com.br
} 
las politicas supranacionales que deben preponderar frente los aspectos internos de las instituciones de educación universitarias.

PALAVRAS CLAVE: Revalidación de diplomas. Politica educativa. Educación superior.

ABSTRACT: The purpose of this paper is to outline the Brazilian Executive, Legislative and Judicial Powers movement in the process of constructing the policy of revalidation of undergraduate diplomas, which stands out in a globalized context. It was based on a analysis of documents produced within the scope of the three powers. From 2002 to 2016, there was approval by the CNE / MEC of disciplinary norms, besides the inclusion of exams and the creation of the Carolina Bori Platform. In 2011, there is the action of the federal legislature, which interposes a bill for automatic revalidation purposes. A total of 3.681 cases were found in the courts, however, there is no indication as to the merits of revalidation. The state acts vigorously in favor of increasing national demand for revalidation and supranational policies that must prevail over the internal aspects of university institutions.

KEYWORDS: Revalidation of diplomas. Educational politics. Higher education.

\section{Introdução}

A revalidação de diplomas estrangeiros de cursos de graduação no Brasil é disciplinada por meio de lei complementar ${ }^{4}$, especificamente pela Lei de Diretrizes e Bases da Educação ${ }^{5}$. Trata-se do ato de dar validade nacional aos títulos obtidos no exterior para viabilizar a atuação profissional do diplomado no território brasileiro.

A lei atribui essa tarefa às universidades públicas que tenham curso equivalente àquele a ser revalidado, abrindo exceções para a existência de acordos de revalidação. No entanto, destaca-se que o Brasil, até o momento, não possui nenhum acordo de reconhecimento automático de diplomas, o que pode ser observado na página do Ministério da Educação (MEC), a qual fornece orientações sobre esse procedimento ${ }^{6}$.

Autores como Alvarez (2015) e Conceição (2012), sinalizam em direção a um movimento de interferência do Executivo Federal, que passa a formular e implementar políticas centralizadoras com fins de otimizar os resultados da revalidação junto às universidades,

${ }^{4}$ Conforme previsto no art. 69 da Constituição Federal.

${ }^{5}$ Refere-se ao art. 48, $\S 2^{\circ}$ da Lei $N^{\circ} 9.394$, de 20 de dezembro de 1996.

6 Disponível no seguinte endereço eletrônico: http://portal.mec.gov.br/busca-geral/322-programas-e-acoes1921564125/revalidacao-de-diploma-graduacao-1444992024/12405-revalidacao-de-diploma-graduacao. Acesso em: 12 fev. 2018. 
indicando a presença de uma política nacional de revalidação de diplomas em detrimento de políticas institucionais.

Grosso modo, esse processo pode ser explicado ao considerar o contexto em que é produzida essa política, em que são sentidos os efeitos da globalização na área da educação, que passa a ser vista como área de interesse do capital.

O processo de globalização em curso atribui ênfase ao aspecto econômico que interfere no político, implicando tensionamentos nas decisões do Estado-Nação diante das influências externas, sinalizadas por meio de uma agenda estruturada globalmente, ainda considerando a constituição de blocos econômicos e suas políticas supranacionais (DALE, 2004; ROBERTSON, 2009). Por outro lado, as políticas sofrem as tensões dos aspectos e valores que ocorrem no microuniverso das próprias instituições (SOUZA, 2016), onde incide o locus da efetivação da revalidação de diplomas.

De forma geral, esse contexto implica em valorização da educação superior como mecanismo de contribuir com desenvolvimento econômico, interferindo positivamente no processo competitivo entre países e regiões.

No âmbito do Mercado Comum do Sul (Mercosul), que se caracteriza como um bloco econômico que conta com a participação do Brasil, desde sua criação, há indicativos a respeito da resistência brasileira em promover revalidação automática dos diplomas originados nos países membros ${ }^{7}$, explicitando possíveis embates no processo de revalidação junto às universidades brasileiras e às políticas supranacionais.

Essa questão ganha contornos de centralidade na agenda do Executivo Federal ${ }^{8}$, considerando, ainda, o processo de internacionalização em curso e a demanda crescente de pedidos de revalidação de títulos estrangeiros, solicitados, inclusive, por brasileiros, o que pode ser identificado como um dos efeitos da "cross border educacion" 9 ".

Assim, parte-se da hipótese de que o Executivo Federal estaria carreando para si a atribuição de formular políticas nacionais voltadas para a revalidação de títulos, indicando procedimentos implementadores às instituições, com fins de facilitação do processo e o consequente atendimento à agenda supranacional.

\footnotetext{
${ }^{7}$ Nesse sentido ver: Krawczyk e Sandoval, 2012; Verhine e Freitas, 2012.

${ }^{8}$ Essa centralidade será melhor explicitada na primeira seção do presente trabalho.

${ }^{9} \mathrm{O}$ termo cross-border education adotado no presente projeto tem como referência o conceito desenvolvido por Knight (2006), que sintetiza o movimento de passagem ou de migração de pessoas, conhecimento, programas, serviços e de currículos entre países para fora de suas jurisdições/fronteiras, com viés comercial. Mantém-se o uso da expressão em inglês, de forma a preservar seu sentido original.
} 
Esta hipótese, por sua vez, se traduz no seguinte problema: como e em que medida o Estado brasileiro está agindo diante da revalidação de títulos, considerando a importância que a temática adquire no contexto das políticas supranacionais e locais?

Diante dessa problemática, o presente trabalho define como seu objetivo delinear o movimento dos Poderes executivo, legislativo e judiciário brasileiro no processo de construção da política de revalidação de diplomas de graduação que está em curso.

Para responder ao problema levantado, partiu-se da análise de documentos produzidos no âmbito dos três poderes constituintes do Estado brasileiro. Para fins didáticos, o trabalho foi dividido em duas seções e considerações finais. Na primeira seção, intenciona-se explicitar o movimento do executivo e do legislativo federal no desenvolvimento da política de revalidação de títulos, destacando a relevância que a temática adquire nesses espaços e as tensões produzidas. A segunda seção apresenta os delineamentos que o Judiciário federal traz ao tema.

\section{A política de revalidação de diplomas: ações dos Poderes Executivo e Legislativo}

A política de revalidação de diplomas estrangeiros esteve na pauta da agenda do Legislativo brasileiro no processo de elaboração da Lei de Diretrizes e Bases da Educação (LDB), publicada em 1996, uma vez que tratou do assunto, o que não ocorreu na legislação anterior $^{10}$.

Apesar de a LDB ter sido publicada em 1996, somente 6 anos depois esse assunto adquire destaque na agenda do Executivo, que passa a publicar resoluções através do Conselho Nacional de Educação (CNE) acerca dos processos de revalidação de diplomas.

A Resolução CNE/CES n ${ }^{\circ}$, em 2002, traz orientações às universidades públicas acerca de encaminhamentos necessários diante de um processo de revalidação de diploma, como a necessidade de constituir uma comissão específica para esse fim. A Resolução CNE/CES nº 8, em 2007, fixa procedimentos a serem realizados durante o processo de revalidação, como prazo para inscrição, recepção de documentos e análise de equivalência. E a Resolução nº 7, em 2009, altera a resolução anterior quanto a recursos para Câmara de Ensino Superior (CES), que só poderão ser feitos em caso de erro, de fato ou de direito.

Observa-se que cada uma das resoluções busca aprimorar a anterior e orientar o desenvolvimento dos processos realizados pelas IES públicas.

${ }^{10}$ Refere-se aqui à Lei no $5.540 / 1968$.

RIAEE - Revista Ibero-Americana de Estudos em Educação, Araraquara, v. 14, n. 3, p. 942-955, jul./set., 2019. E-ISSN: $1982-5587$. 
No mesmo ano de publicação da $\mathrm{LDB}$, a revalidação de diplomas foi debatida na reunião de ministros da educação dos países signatários do Mercosul. Nessa reunião, elaborou-se um documento que recomenda protocolos de admissão de títulos para atividades acadêmicas nos países signatários. E, em 1999, foi aprovado um acordo que prevê a admissão de títulos para esse fim no conjunto do Mercosul. Esse acordo é institucionalizado, em 2005, pelo Legislativo brasileiro, por meio do Decreto $\mathrm{n}^{\mathrm{o}} 5.518$.

As ações que envolvem o Mercosul chamam a atenção de muitos brasileiros que almejam a revalidação de seus diplomas, especialmente os que os obtiveram nos países que fazem parte desse bloco econômico. E, passam a demandar do governo soluções públicas.

Além desses, existem os imigrantes que vivem essa mesma situação, e os beneficiários dos programas de intercâmbio fomentados pelo próprio governo brasileiro, que se somam a essa demanda por revalidação.

Nesse contexto, Villanueva (2013) sustenta que as relações cotidianas entre a sociedade e o Estado tomam forma de problemas e soluções, demandas e ofertas, para os quais cabe busca de soluções.

Dessa forma, ainda no ano de 2009, é aprovada a portaria interministerial do Ministério da Educação (MEC) e do Ministério da Saúde (MS) no 865/2009, que instituiu o Projeto Piloto de Revalidação de Diplomas Médicos, que disponibiliza "exame de avaliação com base em matriz referencial de correspondência curricular, com a finalidade de subsidiar os procedimentos de revalidação conduzidos por universidades públicas”. Esse piloto teve início em 2010 e um ano depois passa a ser um programa permanente, de acordo com a publicação de Portaria Interministerial $n^{\circ}$ 278/2011, que instituiu o Exame Nacional de Revalidação de Diplomas Médicos expedidos por Instituição de Educação Superior Estrangeira (Revalida). Essa legislação específica é justificada pela grande demanda reprimida de diplomas médicos, conforme apresentado na justificativa da criação do programa.

Mesmo que essa legislação busque atender a uma demanda específica, nota-se que a revalidação de títulos se mantém presente na agenda do Executivo brasileiro.

Em 2011, esse assunto passa a fazer parte, também, da agenda do Senado Federal brasileiro, quando o senador Roberto Requião propõe projeto de lei (PL nº 399/2011) alterando o art. 48 da LDB, sugerindo revalidação automática para os diplomas oriundos de cursos de instituições de ensino superior estrangeiras com reconhecida excelência acadêmica. Durante o trâmite do PL, muitas discussões surgem acerca da revalidação automática; são realizadas audiências públicas e há um intenso debate sobre essa questão. As Comissões de Relações Exteriores e Defesa Nacional e, a de Educação, Cultura e Esporte do Senado fazem suas 
propostas de emendas e no projeto final, aprovado e encaminhado à Câmara dos Deputados Federais, não aparece a revalidação automática, mas processo de tramitação simplificada para solicitações que tenham diplomas vindos de tais instituições.

Fica estabelecido no PL nº 399/2011 que, anualmente, o órgão responsável pela coordenação da política nacional de educação divulgará uma relação de cursos, instituiçõos e programas de ensino estrangeiros de excelência, acompanhada de instrução de procedimentos e orientações para a tramitação dos processos de revalidação de diplomas oriundos dessas instituições. Esse projeto foi aprovado pelo Senado em 28 de julho de 2014 e encaminhado à Câmara dos Deputados em 30 de julho do mesmo ano.

Na Câmara dos Deputados, o projeto de lei aguarda a votação, conforme consulta ao processo em julho de 2018. Entretanto, não há propostas de alteração ao projeto enviado pelo Senado e o relator que já emitiu parecer, Deputado Zeca Dirceu, vota por sua aprovação.

No relatório, no qual apresenta seu voto, o relator destaca que apesar de o art. 48 da LDB prever o reconhecimento e registro de diplomas estrangeiros que passem com sucesso por processo de revalidação em universidades públicas, a falta de critérios claros e objetivos torna o processo imprevisível. O relator entende que o PL proposto pelo Senado visa corrigir essa situação através de uma parceria entre universidades e MEC, para estabelecer parâmetros de qualidade e prazos. E ainda, afirma que esses parâmetros de qualidade impedirão que brasileiros se matriculem no exterior em cursos que não tenham condições de serem reconhecidos no Brasil.

Nesse sentido, há uma inversão na característica das agendas públicas, que depois de chegar ao âmbito institucional, quando se busca definição de procedimentos concretos e técnicos, voltam a se constituir em uma agenda sistêmica, com potencial de se tornar uma política pública.

Sobre a agenda, Villanueva (2013) afirma que nem todos os assuntos vão chamar a atenção do governo, uma vez que existem interesses públicos diferentes e, ainda, existe uma lista de prioridades. Com isso, além do Legislativo que passa a agir legiferando sobre o tema, o Executivo coloca novamente o assunto em sua agenda, antes mesmo da definição do Legislativo, demonstrando sua importância. E, através do CNE, publica uma nova resolução sobre revalidação de diplomas, a Resolução n 3 de 22 de junho de 2016. Esse documento traz novas orientações às universidades, definindo prazos e possibilidade de punição aos responsáveis pelo seu não cumprimento.

$\mathrm{O}$ art. 11 dessa resolução traz a possibilidade de processo de revalidação com tramitação simplificada para cursos estrangeiros cujos diplomas já tenham sido objeto de revalidação nos 
últimos 10 anos, assim como cursos que foram acreditados pelo Sistema de Acreditação Regional de Cursos de Graduação do Mercosul (ARCU-SUL) ${ }^{11}$ e diplomas obtidos por meio do Programa Ciências sem Fronteiras.

Essa resolução define que a tramitação simplificada deverá se ater, exclusivamente, à verificação da documentação comprobatória da diplomação no curso, dispensando a análise aprofundada ou processo avaliativo específico. Para esse tipo de tramitação o prazo para conclusão é de até 60 dias, já para tramitação normal o prazo é de 180 dias.

Outra novidade é que o portador de diploma estrangeiro não precisará aguardar abertura de edital da universidade para solicitar o pedido de revalidação, pois essa resolução dispensa o edital. E, também, não será necessária a tradução dos documentos para o português para os que estiverem escritos em francês, inglês e espanhol, por serem consideradas línguas francas utilizadas no ambiente de formação acadêmica.

$\mathrm{O}$ art. $4^{\circ}$ dessa resolução informa que os procedimentos relativos às orientações gerais de tramitação dos procedimentos de solicitação de revalidação serão estabelecidos pelo MEC, através da Secretaria de Educação Superior e deverão ser adotados pelas universidades.

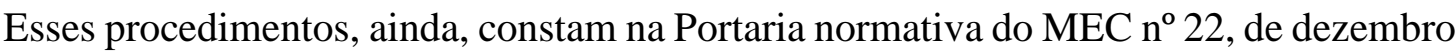
de 2016. Dentre suas orientações estão prazos para emissão de pareceres, como o de 30 dias para a universidade emitir parecer preliminar sobre a documentação entregue na abertura do processo e a necessidade de incluir novos documentos.

Outra orientação importante versa sobre a tramitação simplificada do processo de revalidação de diplomas, conforme anunciado na Resolução CNE/CES n 3/2016. A portaria trata dessa questão no art. 22, e dentre as informações, a que haverá uma lista específica, produzida pelo MEC, com o nome dos cursos que já tenham tido diplomas reconhecidos em universidades diferentes sem realização de atividades complementares, e ficará disponível na Plataforma Carolina Bori ${ }^{12}$. Aos nominados nessa lista, deverá ser realizada a tramitação simplificada.

As ações e medidas desenvolvidas pelo Executivo e pelo Legislativo evidenciam a centralidade que a revalidação de diplomas estrangeiros adquire no contexto do Estado

${ }^{11}$ Em junho de 2008 foi assinado pelos Ministros de Educação da Argentina, Brasil, Paraguai, Uruguai, Bolívia e Chile, o Acordo sobre a criação e implementação de sistema de credenciamento de cursos de graduação para o reconhecimento regional da qualidade acadêmica dos respectivos diplomas no MERCOSUL e Estados Associados. Esse acordo foi homologado pela Decisão CMC n ${ }^{\circ} 17 / 08$.

12 A criação dessa plataforma é mais uma medida do Executivo federal com vistas a disciplinar o processo de revalidação de diplomas. Sua finalidade é propiciar ao portador do diploma o acompanhamento do seu processo. Foi disponibilizada para acesso na internet em 13/12/2016. Essa plataforma será alimentada pelo MEC em parceria com as IES revalidadoras. 
brasileiro, que passa a agir de forma a desenvolver política de caráter nacional, estabelecendo ações que deverão ser realizadas pelas universidades. Essas por sua vez têm acatado, a priori, sem resistência, conforme se pode observar no âmbito do judiciário.

\section{A política de revalidação de diplomas: ações do Poder Judiciário}

O Estado brasileiro é organizado de acordo com a teoria da tripartição do poder do Estado. Entre eles, está o Poder Judiciário, que exerce a função jurisdicional para resolução dos conflitos levados a seu conhecimento, mediante a aplicação do direito vigente na lei e no ordenamento jurídico. Ele tem a função precípua de interpretar e aplicar a lei nos litígios surgidos entre os cidadãos ou entre os cidadãos e o Estado.

Segundo Villanueva (2013), o Estado é concebido como encarregado de solucionar os problemas que as relações entre os cidadãos e a sociedade civil não são capazes de resolver, o que pode ser feito a partir das ações do poder judiciário.

Atualmente tramitam muitas ações e recursos nas instâncias judiciais brasileiras que versam sobre a revalidação de diplomas estrangeiros, o que pôde ser observado com a realização de busca parametrizada no site Jusbrasil ${ }^{13}$, onde é possível encontrar jurisprudência de todos os tribunais brasileiros. Ao utilizar o descritor "revalidação de diploma estrangeiro" foi possível encontrar 3.681 processos que versam sobre a revalidação de títulos de educação superior obtidos no exterior.

Segundo Cury e Ferreira (2009), a consolidação dos direitos sociais fez com que surgisse uma relação direta entre a justiça e a educação, sendo que a partir de 1988, o poder Judiciário passou a ter funções mais significativas na concretização desse direito, materializada por meio de ações judiciais visando a sua garantia e efetividade. A este fenômeno deu-se o nome de “judicialização da educação, que significa a intervenção do poder judiciário nas questões educacionais em vista da proteção desse direito até mesmo para se cumprirem as funções constitucionais do Ministério Público e outras instituições legitimadas” (CURY; FERREIRA, 2009, p. 33).

A CF foi a responsável pela ampliação do rol de direitos civis, políticos, econômicos, sociais e culturais, o que segundo Bonavides (2011), aumentou a expectativa dos cidadãos de

13 Disponível no seguinte endereço eletrônico: http://www.jusbrasil.com.br/jurisprudência. Acesso em: 11 fev. 2017. 
verem cumpridos os direitos e garantias previstas na Carta Magna, fazendo com que a execução deficiente ou a falta de execução das políticas sociais, leve a busca do judiciário.

Essa relação entre política e o direito vem sendo denominada de judicialização da política, na qual uma parte do poder político está sendo transferido das instâncias políticas tradicionais para o poder Judiciário, sendo que a última palavra sobre questões sociais, econômicas ou morais de largo alcance estão tendo sua instância final de decisão perante o poder Judiciário (BARROSO, 2012).

Ao mesmo tempo em que se constatou a importância do judiciário, também se verificou um progressivo desapontamento com a política majoritária, na qual, muitas vezes, o Legislativo não é capaz de normatizar temas controversos da sociedade, cabendo ao Judiciário a resolução desses litígios.

A existência de qualquer questionamento sobre a legitimidade ou eficiência de uma política pública deveria ser respondida nas esferas do Legislativo e do Executivo, pois são estes os responsáveis pela sua formulação e execução. Ocorre, porém, que essa discussão tem caminhado cada vez mais para a esfera do Judiciário, sendo que este tem se posicionado sobre questões políticas e econômicas, e até mesmo decidindo questões administrativas que antes eram resolvidas pelos outros dois poderes.

Ao Judiciário incumbe verificar se estão sendo cumpridos os moldes jurídicos no projeto e na execução das políticas públicas. Cabe a ele confrontar as políticas assumidas com os padrões jurídicos aplicáveis. Sendo assim, muitas vezes, o sistema judiciário é acionado para suprir a função da administração pública que deixou de realizar a prestação social.

Para Barroso (2008), nos últimos anos vem ocorrendo uma constante crise de representatividade, legitimidade e funcionalidade no âmbito do Legislativo, fato este que tem causado a expansão do Judiciário nessa direção, em nome da Constituição, com a prolação de decisões que suprem omissões. Ainda segundo o mesmo autor, este fenômeno tem como positivo o fato de que o Judiciário está atendendo a demandas da sociedade que não puderam ser satisfeitas pelo parlamento, porém, em contrapartida, tem como negativo o fato de expor as dificuldades que o Legislativo enfrenta.

Observa-se que, em se tratando dos processos ajuizados sobre a revalidação de diploma, é possível verificar que diversos são os motivos que levam à busca do Judiciário ${ }^{14}$ : revalidação

${ }^{14}$ Refere-se aos seguintes processos: ARE 851225 AgR, Relator (a): Min. Roberto Barroso, Primeira Turma, julgado em 28/10/2016, PROCESSO ELETRÔNICO DJe-243 DIVULG 16-11-2016 PUBLIC 17-11-2016. ADI 5341 MC-Ref / AC - ACRE - Referendo na Medida Cautelar na Ação Direta de Inconstitucionalidade Relator (a): Min. EDSON FACHIN - Julgamento: 10/03/2016. 
automática de título de graduação, sem a observância da LDB; limitação de participação nos processos de revalidação por parte das universidades avaliadoras; universidades que estabelecem prazo exíguo para a apresentação dos documentos necessários à instrução do procedimento administrativo relativo à pretendida revalidação; cobrança de taxa exorbitante para revalidação de diploma; não observância, pela universidade, das etapas previstas na legislação, pois não pode submeter o requerente à prova ou exame antes do julgamento de equivalência dos currículos pela comissão designada e divergência sobre o juízo competente para analisar os processos de revalidação. Enfim, a maioria decorre da falta de uma legislação que regulamente uniformemente os procedimentos administrativos sobre a revalidação, o que influenciou o Executivo a incluir em sua agenda a política de revalidação de diplomas e se debruçar sobre ela.

A judicialização dos processos de revalidação de diploma de graduação estrangeiro demonstra que há uma falha no processo administrativo, o que acaba por atingir a concretização de uma política pública educacional.

Nesse contexto, é possível observar que a política de revalidação de diplomas também se encontra na agenda do Judiciário brasileiro com mais de 3.500 processos em andamento e os motivos que causam essas demandas podem ser semelhantes aos que a mantêm nas agendas do Executivo e do Legislativo.

\section{Considerações finais}

O presente trabalho buscou explicitar as interfaces entre os Poderes constituintes do Estado brasileiro na definição de políticas para a revalidação de diplomas de graduação estrangeiros, uma vez que essa temática adquiriu relevância a partir da ampliação da demanda interna e das influências das políticas supranacionais.

Nesse sentido, buscou-se analisar as medidas desenvolvidas no âmbito do Executivo, do Legislativo e do Judiciário, concretizadas sob a forma de documentos, normas e decisões

RE 676925, Relator (a): Min. Luiz Fux, Primeira Turma, julgado em 22/05/2012, ACÓRDÃO ELETRÔNICO DJe-121 DIVULG 20-06-2012 PUBLIC 21-06-2012.

AI 771855 AgR, Relator(a): Min. Dias Toffoli, Primeira Turma, julgado em 13/03/2012, ACÓRDÃO ELETRÔNICO DJe-081 DIVULG 25-04-2012 PUBLIC 26-04-2012

RE 676925, Relator (a): Min. Luiz Fux, Primeira Turma, julgado em 22/05/2012, ACÓRDÃO ELETRÔNICO DJe-121 DIVULG 20-06-2012 PUBLIC 21-06-2012.

AI 771855 AgR, Relator(a): Min. Dias Toffoli, Primeira Turma, julgado em 13/03/2012, ACÓRDÃO ELETRÔNICO DJe-081 DIVULG 25-04-2012 PUBLIC 26-04-2012

RE 580215 AgR, Relator (a): Min. Cármen Lúcia, Primeira Turma, julgado em 15/09/2009, DJe-195 DIVULG 15-10-2009 PUBLIC 16-10-2009 EMENT VOL-02378-06 PP-01222. 
julgadas, em que se pode observar que a ação pública ocorre de forma intensa, recente e abrangente.

A LDB, aprovada em 1996, atribuiu a revalidação de diplomas às universidades públicas, que deveriam formular políticas institucionais para a sua implementação. No entanto, no período de 2002 a 2016 é formulado um conjunto de normas advindas do CNE, órgão vinculado ao Executivo federal, que passa a formular políticas nessa direção, o que explicita a adesão da temática da revalidação na agenda sistêmica do Estado brasileiro. Nesse mesmo sentido foi a ação do Legislativo que interpõe, em 2011, projeto de lei para fins de revalidação automática, que após passar por alterações, já está em fase de conclusão.

Além da dimensão regulatória da política constituída sob a forma de normas e leis, há ainda a adoção de exames estandardizados para fins de atestar a correspondência curricular, implementados a partir de 2010, e o desenvolvimento da Plataforma Carolina Bori, em 2016, com a finalidade de viabilizar transparência e agilidade ao processo.

Desde 2006, há ações interpostas ao Supremo Tribunal Federal, última instância recursal do Judiciário, contra as negativas de revalidação por parte das universidades. Ao todo foram encontrados 3.681 processos nos tribunais de justiça utilizando o descritor "revalidação de diplomas estrangeiros". No entanto, não se verifica posicionamento do Judiciário com relação ao mérito da revalidação.

O que se pode compreender desse processo eivado de embates e tensões é que o Estado age, e age vigorosamente, em favor da demanda interna crescente e das políticas supranacionais que devem preponderar frente aos aspectos e valores internos das instituições universitárias.

\section{REFERÊNCIAS}

ALVARES, Adriana de Lourdes Trentin. 2015. 170f. Educação superior além-fronteiras: um olhar sobre as estratégias institucionais para atratividade de estudantes brasileiros. Dissertação (Mestrado em Educação) da Faculdade de Educação, Universidade Federal da Grande Dourados, 2015.

BARROSO, Luís Roberto. Ano do STF: Judicialização, ativismo e legitimidade democrática. Revista Consultor Jurídico, 22 de dezembro de 2008. Disponível em: http://www.conjur.com.br/2008-dez-22/judicializacao_ativismo_legitimidade_democratica. Acesso em: 20 fev. 2017.

BARROSO, Luís Roberto. Judicialização, ativismo judicial e legitimidade democrática. [Syn] Thesis, Rio de Janeiro, v.5, n. 1, p.23-32, 2012.

BONAVIDES, Paulo. Do Estado liberal ao Estado Social. 8 ed. São Paulo: Malheiros Editores, 2007. 
BRASIL. Constituição da República Federativa do Brasil (1988). Disponível em: http://www.planalto.gov.br/ccivil_03/Constituicao/Constituicao.htm. Acesso em 15 abr. 2016.

BRASIL. Lei n ${ }^{\circ}$ 9.394, de 20 de dezembro de 1996. Estabelece as diretrizes e bases da educação nacional. Portal da Subchefia de Assuntos Jurídicos da Casa Civil da Presidência da República: Leis Ordinárias. Brasília: Casa Civil da Presidência da República do Brasil, 1996. Disponível em: http://www.planalto.gov.br/ccivil_03/Leis/L9394.htm Acesso em: 02 out. 2014.

BRASIL. Conselho Nacional de Educação. Resolução CNE/CES nº 1 , de 29 de janeiro de 2002. Estabelece normas para a revalidação de diplomas de graduação expedidos por estabelecimentos estrangeiros de ensino superior. Brasília: Diário Oficial da União, Seção 1, p. 11, fev. 2002. Disponível em:

http://portal.mec.gov.br/index.php?option=com_content\&view=article\&id=13192\%3Aresoluc ao-ces-2002\&catid=323\%3Aorgaos-vinculados\&Itemid=866. Acesso em: 27 out. 2016.

BRASIL. Decreto no $\mathbf{0}$ 5.518, de 23 de agosto de 2005. Promulga o acordo de admissão de títulos e graus universitários para o exercício de atividades acadêmicas nos Estados Partes do Mercosul. Brasília, DF, 2005. Disponível em: http://www.planalto.gov.br/ccivil_03/_Ato2004-2006/2005/Decreto/D5518.htm. Acesso em: 27 out. 2016

BRASIL. Conselho Nacional de Educação. Resolução CNE/CES nº 8, de 04 de outubro de 2007. Altera o Art. $4^{\circ}$ e revoga o art. 10 da Resolução CNE/CES n ${ }^{\circ} 1 / 2002$, que estabelece normas para a revalidação de diplomas de graduação expedidos por estabelecimentos estrangeiros de ensino superior. Brasília, DF: Diário Oficial da União, 2007. Disponível em: http://portal.mec.gov.br/cne/arquivos/pdf/2007/rces008_07.pdf. Acesso em: 27 out. 2016.

BRASIL. Conselho Nacional de Educação. Resolução CNE/CES n ${ }^{\circ} 7$, de 25 de setembro de 2009. Altera o $\$ 2^{\circ}$ do art. $8^{\circ}$ da Resolução CNE/CES no 8, de 4 de outubro de 2007, que estabelece normas para a revalidação de diplomas de graduação expedidos por estabelecimentos estrangeiros de ensino superior. Brasília: Diário Oficial da União, 28 set. 2009, Seção 1, p. 30. Disponível em: http://portal.mec.gov.br/dmdocuments/rces007_09.pdf. Acesso em: 12 fev. 2016.

BRASIL. Portaria Interministerial $n^{\circ} 865$, de setembro de 2009. Aprova o Projeto Piloto de revalidação de diplomas de médico expedido por universidades estrangeiras. MEC/MS.

Brasília: Diário Oficial da União. 2009. Disponível em: http://www.in.gov.br/autenticidade.html. Acesso em: 10 jan. 2017.

BRASIL. Portaria Interministerial no 278, de 17 de março de 2011. Institui o Exame Nacional de Revalidação de Diplomas Médicos expedidos por universidades estrangeiras (Revalida). Brasília, DF: Diário Oficial da União. 18 de março de 2011. Seção 1, p. 12, nº 53, ISSN 1677-7042. Disponível em: http://www.in.gov.br/autenticidade.html. Acesso em: 10 abr. 2017.

BRASIL. Conselho Nacional de Educação. Resolução CNE/CES nº 3, de 22 de junho de 2016. Dispõe sobre normas referentes à revalidação de diplomas de cursos de graduação e ao reconhecimento de diplomas de pós-graduação stricto sensu (mestrado e doutorado), 
expedidos por estabelecimentos estrangeiros de ensino superior. Brasília: Diário Oficial da União, 23 de junho de 2016, Seção 1, págs. 9-10. Disponível em: http://www.in.gov.br/autenticidade.html. Acesso em: 20 dez. 2016.

BRASIL. Ministério da Educação. Portaria Normativa nº 22, de 13 de dezembro de 2016. Dispõe sobre normas e procedimentos gerais de tramitação de processos de solicitação de revalidação de diplomas de graduação estrangeiros e ao reconhecimento de diplomas de pósgraduação stricto sensu (mestrado e doutorado), expedidos por estabelecimentos estrangeiros de ensino superior. Brasília: Diário Oficial da União, 14 de dezembro de 2016, Seção 1, págs. 9-11. Disponível em: http://www.in. gov.br/autenticidade.html. Acesso em: 20 dez. 2016.

CONCEIÇÃO, Jullie Cristhie da. O processo de revalidação de diplomas de cursos de graduação no Brasil: um olhar sobre o projeto piloto de medicina. Revista Ibero-Americana de Estudos em Educação, v. 7, n. 3, 2012.

CURY, Carlos Roberto Jamil; FERREIRA, Luiz Antônio Miguel. A judicialização da educação. Revista CEJ, Brasília, ano 13, n. 45, p. 32-45, abr./jun. 2009.

DALE, Roger. Globalização e educação: demonstrando a existência de uma "cultura educacional mundial comum" ou localizando uma "agenda globalmente estruturada para a educação"? Educação \& Sociedade, Campinas, v. 25, n. 87, p. 423-460, maio/ago. 2004

KNIGHT, Jane. Higher education crossing border: a guide to implications of the General Agreement on Trade in Services (GATS) for cross border education. Paris: UNESCO, 2006. Disponível em: http://unesdoc.unesco.org/images/0014/001473/147363E.pdf. Acesso em: 10 jan. 2017.

KRAWCZYK, Nora; SANDOVAL Salvador Antonio Mireles. O Processo de Regionalização das Universidades do Mercosul: um estudo exploratório de regulação supranacional e nacional. Educação e Realidade, Porto Alegre, v. 37, n. 2, p. 647-668, 2012.

MERCOSUL. Decisão n ${ }^{\circ}$ 17/08. $35^{\circ}$ Conselho do Mercado Comum. San Miguel de Tucumán, 17 de junho de 2008. Disponível em: http://www.capes.gov.br/images/stories/download. Acesso em: 17 jul. 2015.

PALUMBO, Dennis James. Public policy in America: government in action. 2a. ed. Florida - EUA: Harcourt Brace \& Company, 1994.

ROBERTSON, Susan L. O processo de Bolonha da Europa torna-se global: modelo, mercado, mobilidade, força intelectual ou estratégia para construção do Estado?. Revista Brasileira de Educação, Rio de Janeiro, v. 14, n. 42, p. 407-422, dez. 2009.

SOUZA, Ângelo Ricardo de. A teoria da agenda globalmente estruturada para a educação e sua apropriação pela pesquisa em políticas educacionais. Revista Brasileira de Política e Administração da Educação - RBPAE, Goiânia, v. 32, n.2, p. 463 - 485, maio/ago. 1916.

VERHINE, Robert Evan; FREITAS, Antônio Alberto da Silva Monteiro de. A avaliação da educação superior: modalidades e tendências no cenário internacional. Revista Ensino Superior, Campinas, p. 16 - 39. Out. 2012. Disponível em: 
https://www.revistaensinosuperior.gr.unicamp.br/edicoes/ed07_outubro2012/ARTIGO_PRIN CIPAL.pdf. Acesso em: 21 jan. 2017.

VILLANUEVA, Luis Fernando Aguilar. Problemas públicos e agenda de gobierno. México: Miguel Ángel Perrúa, 2013.

\section{Como citar este artigo:}

REAL, Giselle Cristina Martins.; MARRAN, Ana Lucia.; ZENI, Kelei. A política de revalidação de diplomas estrangeiros: interfaces entre o Executivo, Legislativo e Judiciário. Revista Ibero-Americana de Estudos em Educação, Araraquara, v. 14, n. 3, p. 942-955, jul./set., 2019. E-ISSN: 1982-5587. DOI: 10.21723/riaee.v14i3.11573

Data de Submissão: $18 / 07 / 2018$

Revisões requeridas: 15/09/2018

Aceite em: 18/10/2018

Publicado em: 25/03/2019 